\title{
NA DANÇA TANTO SEU OBJETO QUANTO SEU INSTRUMENTO PROFISSIONAL É O PRÓPRIO CORPO
}

\author{
DRA. LÍVIA TENORIO BRASILEIRO \\ Mestrado em Educação pela Universidade Federal da Pernambuco (UFPE) e Doutorado em Educação \\ pela Universidade Estadual de Campinas (UNICAMP), Professora da Escola Superior de Educação \\ Física (ESEF) da Universidade de Pernambuco (UPE), Grupo de Estudos Etnográficos em Educação \\ Física e Esportes (ETHNÓS) (Recife - Pernambuco - Brasil) \\ E-mail: livtb@hotmail.com
}

\section{RESUMO}

O presente estudo é um fragmento da tese Dança - Educação Física: (in)tensas relações, que teve como objetivo: analisar os sentidos e significados produzidos nas propostas curriculares dos cursos de formação de professores de Educação Física e Dança, a respeito do conhecimento dança. Caracterizou-se como uma pesquisa documental que teve como principal fonte os projetos pedagógicos dos cursos de Licenciatura em Dança e Licenciatura em Educação Física de duas instituições brasileiras, sendo delimitado um par na Bahia (UFBA) e o outro em São Paulo (UNICAMP). Ao analisar os projetos pedagógicos, identificamos que o termo corpo tem presença marcante, tendo na dimensão do fazer corporal seu maior enfoque. Mas, o que significa para uma área de conhecimento ter o corpo como referência fundante?

PALAVRAS-CHAVE: Dança; Educação Física; corpo; formação. 
O presente estudo é um fragmento da tese Dança - Educação Física: (in) tensas relações,' integrando o capítulo referente às reflexões sobre a dança no campo do conhecimento e da linguagem. A tese teve como objetivo: analisar os sentidos e significados produzidos nas propostas curriculares dos cursos de formaçã̃o de professores de Educação Física e Dança, a respeito do conhecimento dança.

Caracterizou-se como uma pesquisa documental que teve como principal fonte os projetos pedagógicos dos cursos de Licenciatura em Dança e Licenciatura em Educação Física de duas instituições brasileiras, sendo delimitado um par na Bahia - Universidade Federal da Bahia (UFBA) e o outro em São Paulo - Universidade Estadual de Campinas (UNICAMP).

A partir da leitura dos projetos foi possível destacar inúmeros fragmentos que permitiram refletir sobre a compreensão apresentada nos documentos, a respeito da dança. Para análise destacaram-se cinco fragmentos que perpassavam o foco da pesquisa, são eles: "A dança como área de conhecimento" e "A dança como conhecimento clássico da Educação Física"; "Na dança tanto seu objeto quanto seu instrumento profissional é o próprio corpo"; "Linguagem da dança - Linguagens corporais - Linguagens do movimento - Linguagens artísticas"; "A dança é uma manifestação artística que tem presença marcante na cultura popular brasileira"; e "No momento damos, a essa área de conhecimento que se constrói a partir dessas atividades, a denominação de Cultura Corporal".

Neste artigo destaca-se o fragmento "Na dança tanto seu objeto quanto seu instrumento profissional é o próprio corpo", sendo apresentado como ele vai sendo elucidado ao longo dos projetos.

\section{A PRESENÇA MARCANTE DO TERMO CORPO EM DISCUSSÃO}

O fragmento em análise realça que o termo corpo tem presença marcante nos projetos dos cursos de Licenciatura em Educação Física e em Dança, aparecendo o tema da relação corpo e mente, do mercado e do culto ao corpo como fundantes nas discussões sobre essas áreas.

O Curso de Dança da UNICAMP inicia sua apresentação evidenciando que vivemos numa cultura racionalista ocidental que "[...] por séculos seguidos negou ou reprimiu o conhecimento do corpo humano", sendo o século $X X$ um palco de ruptura com essa cultura em busca de novas referências, dando destaque às teorias psicológicas e sociológicas na denúncia da "repressão corporal". Nesse movimento,

I. Pesquisa desenvolvida com bolsa PICDT/CAPES, no período de junho/2006 a fevereiro/2009. 
[...] pesquisadores de diferentes áreas passaram a estudar a dinâmica do corpo, desenvolvendo inúmeras novas técnicas de trabalho corporal", das quais a área de dança recebeu influências dos trabalhos que destacavam a "liberação dos movimentos e criatividade (UNICAMP, 2006, p. I).

fragmento destacado, para este texto, é apresentado na justificativa deste curso, quando da afirmação de que a universidade considera a necessidade de aliar conhecimento teórico à experiência prática, portanto, "A Dança, desde sua recente implantação no ensino Universitário, deparou-se com o desafio de realizar esta aliança, uma vez que tanto seu objeto quanto o seu instrumento profissional é o próprio corpo" (UNICAMP, 2006, p. 3).

O estudo do corpo, que já tinha espaço na universidade, especialmente no interior das áreas médicas, ganha um novo lugar nos estudos do corpo em movimento, nesse caso, na manifestação artística dança.

Para o Curso de Dança da UFBA, "re-significar" a dança implica entender as exigências do século em que vivemos, pois

Considerando recentes descobertas científicas, temos sido forçados a reavaliar certos valores tradicionais que hegemonicamente têm regido o comportamento, a percepção e a evolução humana nos últimos séculos do ocidente. Um exemplo é a polêmica relação entre os conceitos de corpo e mente. Dançarinos, acreditamos, que no fundo sempre compreenderam o que recentemente têm constatado cientistas e filósofos - uma intrínseca e recíproca interação que envolve o corpo e a mente enquanto dimensões de um único sistema (continuum) na experiência e expressão humanas (UFBA, 2004, p. I0).

Este curso toma essa polêmica como ponto de reflexão para justificar a necessidade da reforma curricular frente aos avanços científicos na contemporaneidade, constatando que essa mudança na concepção do corpo e mente afeta diretamente os conteúdos e os métodos tradicionalmente usados no ensino de arte e, no caso da dança, essa perspectiva

[... que rompe com o pensamento fragmentado e com a noção de instâncias estanques de atuação humana, pode ser adotada como um fundamento básico de orientação, estruturação e concepção da práxis pedagógica da dança (UFBA, 2004, p. 10).

Nos cursos de Educação Física, observa-se, no projeto da UNICAMP, uma preocupação com a necessidade de refletir sobre essa dimensão do corpo, alertando na discussão sobre seus campos de atuação, que

Um curso de graduação de qualidade deve considerar a dinâmica do campo profissional, evitando ser subserviente aos seus apelos, correndo atrás dos modismos propagados 
pelo mercado e amplamente divulgados e explorados pela mídia. No caso da Educação Física, este processo parece ser ainda mais contundente, em função da grande repercussão do fenômeno esportivo mundial e da moda relacionada ao corpo e à atividade física (UNICAMP, 2005, p. 8).

Com perspectiva semelhante, o Curso de Educação Física da UFBA, ao apresentar as "Competências globais humanas e habilidades a serem desenvolvidas", também alerta para o fato de que

A educação e a Educação Física, o esporte e lazer são formas de ação político-social que dão rumo à formação de um povo e, portanto, formar professores voltados exclusivamente para mercados de trabalho ligados à industria da beleza, do culto ao corpo - a corpolatria voltados ao esporte de espetáculo, ao esporte de alto rendimento e "rendimentos, lucros", compromete o desenvolvimento de um dado projeto histórico (UFBA, 2007, p. 23).

Estes cursos explicitam, desta forma, o lugar do corpo na história da sociedade ocidental. Os estudos da história, em especial os estudos do corpo, ganham cada vez mais importância frente à impossibilidade de estudar o ser humano em sociedade sem fazê-lo tomando a história de sua vida; portanto, realizar a história do ser humano é realizar a história do que o constitui, entendendo o corpo como materialidade humana (SANT'ANNA, 200I).

Dentre as inúmeras possibilidades de estudar o corpo (tais como a culinária, a saúde, a religião, a estética, a psicologia, a educação), pode-se conhecer como se transformaram os cuidados de si, os hábitos de higiene, as preocupações com a beleza, o tratamento das doenças, os seus hábitos de civilidade (SENNET, 1997).

Contudo, será a natureza biológica o maior palco de explicação do corpo na sociedade ocidental, através especialmente da medicina, na qual desmembrar o corpo, conhecer suas partes, compreender suas funções, suas inervações, seus líquidos constituintes, vem sendo seu constante desafio (SOARES, 1998; TERRA, 2007).

Os cursos de Educação Física e Dança têm fortemente essa marca dos estudos das áreas médicas. No caso da Educação Física, os estudos de anatomia, fisiologia, cinesiologia, bioquímica, biomecânica, dão sustentação à sua base nas ciências da saúde; no caso da Dança, algumas dessas disciplinas apresentam-se na intenção de estudar o corpo, base fundamental de sua organização. Porém, os estudos do corpo se deram, quase exclusivamente, com o corpo morto, sem movimento, inerte, enquanto a centralidade dessas áreas é o corpo em movimento, o corpo que joga, que faz esporte, se exercita, encena, desafia, luta, brinca.

Entender o corpo como materialidade da existência humana implica compreendê-lo além de seu aspecto biológico. Dessa forma, estudos no campo da história dedicaram-se a perceber os processos de civilidade marcados nesse lugar visível. Os 
modos de civilizar o ser humano têm marcas fundamentais no corpo, especialmente no controle dos seus gestos. Para situar esse campo, recorro aos estudos de Revel ( 199 |) e Haroche (1998); eles compreendem que uma sociedade monárquica e disciplinar apresentou formas de civilidade que se inscreveram no corpo, pois

\footnotetext{
É a maneira como a ordem se exprime material, física e concretamente que nos interessa aqui. Pelas regras da etiqueta e do protocolo, pelas marcas exteriores das prerrogativas, a ordem inscreve-se nos gestos, nas atitudes, nas posturas corporais. A precedência, que denota uma ordem, distribui e reparte, por assim dizer, os indivíduos no espaço das instituições do Antigo Regime, segundo seus títulos, suas condições, suas hierarquias, seus cargos, sua ordem. A ordem inscreve-se assim nos corpos e entre os corpos (HAROCHE, 1998, p. 83).
}

E, na constituiç̧ão dessa ordem, a dança e os exercícios físicos fizeram-se presentes na perspectiva de domínio sobre o corpo. No caso da dança, afirma-se que "Na corte, a dança é talvez a forma mais acabada e complexa da auto-apresentação disciplinada. Arte social, mostra o corpo apenas para melhor demonstrar o domínio sobre ele" (REVEL, 1991, p. 199).

Todavia, será na escola que se buscará a civilidade para todos, num processo de escolarização da civilidade, já que "É preciso acrescentar-Ihe uma disciplina, que só pode ser uma aprendizagem socializada pela escola. A partir daí, a civilidade tende a tornar-se um exercício escolar destinado a dispensar uma instrução inextricavelmente religiosa e cívica" (REVEL, 1991, p. 179).

O corpo moralizado convive e dá existência aos homens, mulheres e crianças nas sociedades monárquicas e, desde que foi inserido no processo de escolarização, busca civilizá-los, vindo até os nossos dias nesse movimento. A escola, espaço e tempo de ensino-aprendizado, continua tendo nas normas de conduta sua sustentação, suas classes, suas progressões; o lugar do professor e do aluno, seus espaços e atividades definidos dão um sentido próprio a esse lugar.

A escola traz, marcadamente, a discussão complexa de que a humanidade colocou-se entre corpo e alma, corpo e mente, corpo e espírito, como instâncias diferenciadas do ser humano, sendo sempre o corpo submisso à alma, à mente, ao espírito. Diferenciando as dimensões da natureza e da cultura, vai-se ter na natureza sua maior sustentação de estudos e preocupações. Desse modo, viveu-se ao longo dos séculos com uma forte diferenciação entre ações corporais e intelectuais, sendo a dimensão intelectual privilegiada no espaço de escolarização.

Contraditoriamente, o que se vê nas últimas décadas é a expansão dos estudos sobre o corpo. O corpo vem sendo explorado intensificadamente, não só pelas áreas médicas, na busca de sua melhor depuração, longe de doenças, má 
formação, assim como pela mídia, turismo, tecnologia etc. (SANT'ANNA, 200 I; FRAGA, 200I).

Nesse movimento, também se produziram estudos questionando os modelos, em busca de novas formas de conhecer, explorar a gestualidade de forma consciente e sensível, e são justamente esses estudos que os cursos de Dança acreditam que alimentam suas reformulações, conforme citado anteriormente, bem como a Educação Física deles se apropria em suas discussões atuais.

Os cursos de formação em estudo têm na dimensão do fazer corporal seu maior enfoque. Mas, o que significa para uma área de conhecimento ter o corpo como referência fundante? Vive-se numa sociedade em que o corpo ganhou durante séculos pouca atenção, ou melhor, a atenção dedicada ao mesmo era baseada em seu controle. Nas últimas décadas, viu-se a expansão desenfreada de uma performance corporal, em que a beleza, a forma, a força, foram os alvos principais. Vale registrar o processo de esportivização e a indústria da beleza, que crescem continuamente e expressam novas formas de controle.

Os cursos analisados procuram compreender a Dança e a Educação Física como constituintes das possibilidades corporais que o ser humano construiu e, tendo sua base de sustentação no corpo, como seu objeto e seu instrumento profissional, precisam dedicar-se aos estudos do corpo de forma a ampliar as possibilidades de entender as relações e as interações do ser humano em sociedade. Em consonância com Bakhtin (2003), implica em entender os corpos como signos não verbais, que têm na sua exterioridade uma linguagem não verbal. Signos esses que foram, ao longo da história da humanidade, compreendidos, quase exclusivamente, como objeto a ser controlado, disciplinado, normatizado.

A partir dessas referências, entendo que para escrever a história da humanidade faz-se necessário ler as inscrições corporais presentes nela, não em uma análise individualizante, já que nessa perspectiva o corpo de um não é o bastante, pois um necessita do outro em interação social, como enfatiza Bakhtin (2003, p. 14): "Ao olharmos para nós mesmos com os olhos do outro, na vida sempre tornamos a voltar para nós mesmos, e o último acontecimento, espécie de resumo, realiza-se em nós nas categorias da nossa própria vida".

Nessas relações entre eu e outro, em constante processo de interação

[...] o sujeito apreende sua própria corporeidade e expressividade pela/na mediação da corporeidade e possibilidade expressiva desse outro. Nessas relações, o corpo é elaborado como um eu-para-o-outro e um eu-para-si (FONTANA, 2007, p. 6).

Compreender esses processos de constante interação humana, expressos no jogo, na dança, na luta, na ginástica e nas demais manifestações que têm o corpo 
como signo não verbal é uma tarefa em consonância com a apontada por Silva (2007, p. xi, xiii), de "[...] construir referências para melhor compreender o humano em suas possibilidades corporais".

O lugar que o corpo ocupa no curso de Dança da UNICAMP é de centralidade. Desse modo, o fragmento "na dança tanto seu objeto quanto o seu instrumento profissional é o próprio corpo" ganha destaque. Esse lugar que dá existência ao ser humano vai ser destacado como o objeto da dança, ou seja, sobre o que ela estuda e o lugar no qual ela acontece, ganhando visibilidade.

Importante destacar a diferenciação de que um curso dessa natureza estuda o corpo em movimento; e não é qualquer movimento, é o movimento humano na manifestação artística, o gesto significativo artístico. Dessa forma, o curso tem como estrutura o estudo do corpo e do seu movimento, por meio do desenvolvimento técnico-artístico.

Ao definir o perfil do licenciado, afirma-se que: "Deseja-se formar o professor de dança que adquire e gera conhecimento sensível, próprio de sua corporeidade". Enfatizando que "[...] a formação do dançarino, artista e professor se realiza no corpo do sujeito e que a falta desta integração poderá ocasionar danos ao mesmo" (UNICAMP, 2006, p. 14).

Um professor de dança deve ser um artista, um profissional que tem experiência acumulada em si, que potencializará junto aos seus alunos os conhecimentos da dança através de atividades corporais, como destaca o projeto: "[...] tanto no ato de encenar como no ato de educar, o professor deve ser necessariamente um artista, transmissor de um conteúdo apreendido, vivenciado e aprofundado através de sua trajetória artístico-acadêmica" (UNICAMP, 2006, p. I 5).

A trajetória desses professores é de fundamental importância nessa formação, por isso, este curso exige no processo de seleção uma prova de aptidão, ${ }^{2}$ que busca avaliar o nível dos alunos que chegam a esse processo, e a possibilidade dos mesmos estarem aptos a acompanhar um curso de Dança que tem as características acima mencionadas. Numa reportagem sobre as provas de aptidão da UNICAMP de 2008, é apresentada sua intenção, por uma das avaliadoras e professora do curso:

São avaliados critérios como postura, domínio corporal, ritmo, orientação espacial, percepção e memória do movimento, criatividade, e comunicação e versatilidade. "O trabalho corporal do bailarino equivale ao de um atleta", enfatizou. Neste ano, a nota será composta pela média simples de duas provas: um olhar técnico e outro criativo. Cada uma delas vale 24 pontos. Caso o candidato obtenha nota menor que 8 pontos em qualquer uma das provas, ele terá nota final igual a zero, sendo eliminado da opção (UNICAMP, 2008).

2. Na UNICAMP, há prova específica de aptidão para os cursos de Arquitetura e Urbanismo, Artes Cênicas, Artes Visuais, Dança e Música. 
Uma questão chama atenção: deve ser o trabalho corporal do professor de dança equivalente ao de um atleta, em um curso de formação de professores, conforme citado anteriormente: "O trabalho corporal do bailarino equivale ao de um atleta"?

Destarte, os alunos que entram neste curso têm uma formação anterior mínima para situar-se nesse processo em que a dança faz-se no corpo. E, ao entrarem, terão uma formação focada na dimensão corporal e artística, através de "ateliês", sendo entendidos como "[...] um espaço de construção de um saber que requer um formato diferente daquele que constitui as disciplinas atuais do Curso de Dança". Reorganizando sua forma de apresentação das disciplinas, busca-se integrar esse processo de construção do conhecimento corporal e artístico. Para isso, nesse espaço

O aluno, ao mesmo tempo em que aprende pelo convívio com aquele que já vivenciou este saber em seu corpo, é estimulado a construir sua própria trajetória, para aquisição de um amplo conhecimento em dança. Trata-se, portanto, de unir as habilidades às competências de refletir e compreender criticamente os fundamentos que organizam um conhecimento específico. Trata-se de um saber das artes, entendido, como tecido artesanal, construído gradativamente através da aprendizagem do sensível, do olhar focado não só no corpo que dança, mas na sua relação consigo próprio e com o mundo (UNICAMP, 2006, p. 16).

Vale registrar que o curso de Dança da UFBA também realiza prova de habilidades específicas na sua seleção, tomando como referência o desempenho técnico e interpretativo, o desempenho criativo e a apreciação estética. ${ }^{3}$ Este curso tem na sua composição três eixos estruturantes: Estudos do corpo, Estudos dos processos criativos e Estudos crítico-analíticos. Sendo o primeiro dedicado aos estudos do corpo, entendido como

Estudos sobre e com o corpo visando a consciência e o aprimoramento técnico-expressivo do aluno, assim como maior conhecimento e reflexão crítica e integrada (teoria e prática) dos elementos e princípios que envolvem o desempenho corporal/expressivo em dança. Conceitos e perspectivas acerca das concepções do corpo e de aspectos inter-relacionados: científicos, filosóficos, sociológicos, psicológicos e culturais (UFBA, 2004, p. 17).

Este curso tem, em sua estruturação, a mesma preocupação que a do curso da UNICAMP, de que através de sua constituição curricular, permita aos alunos, que já possuem um conhecimento artístico prévio, ampliar sua base de formação, dando destaque ao espaço em que vai experimentar em seu próprio corpo esses processos e descobertas.

3. Na UFBA, há prova de habilidades específicas para os cursos de Belas-Artes, Dança, Teatro e Música. 
Os cursos de Educação Física, por sua vez, têm em sua estruturação um leque amplo de disciplinas que tomam o corpo como objeto de estudo, com estudos do aparelho locomotor, dos sistemas circulatório, respiratório, nervoso, dos metabolismos, dos processos de crescimento e desenvolvimento, etc. Além do estudo teórico-prático de diversas manifestações corporais, tais como: atletismo, ginástica, natação, dança, voleibol, futsal, handebol, dentre outras.

Muitos desses cursos tiveram, até a década de 1990, a presença dos testes de habilidades físicas no processo de seleção inicial. Porém, nos dias atuais, estes permanecem em pouquíssimos cursos em nosso país. Os testes buscavam classificar e excluir os candidatos através de avaliações de condicionamento físico, que incluíam corrida, nado e exercícios de habilidades diversas. A retirada desses testes teve como justificativa a compreensão de que seus alunos não precisam ter de antemão um conhecimento corporal esportivo ou um condicionamento físico, posto que o curso não seria para formar atletas e sim professores e/ou pesquisadores para intervir profissionalmente em diferentes campos, além da presença crescente e ativa de portadores de necessidades especiais nas atividades físicas e que eram impedidos de concorrer no processo de seleção.

As pessoas que estão envolvidas com o universo profissional da Arte e da Educação Física têm em comum, em sua maioria, trajetórias que apresentam um contato anterior com as manifestações artísticas e corporais, nesse último caso especialmente as esportivas. Chegam às escolas de formação com uma bagagem anterior, que nem sempre é necessário que seja demonstrada com uma prova de habilidades.

Esse é um processo de formação que parte do pressuposto de que os alunos já entram com uma trajetória construída e/ou em construção. Interessante notar que Arte e Educação Física têm em sua história a presença da seleção por habilidades para o curso de vestibular no ensino superior, com a justificativa do que já se sabe antes do ingresso no curso e apresentando a perspectiva de que esses cursos serão espaços de aperfeiçoamento, e nisso eles diferenciam-se da maioria dos cursos de formação.

As demais áreas, em sua quase totalidade, nunca exigiram esses percursos, esses saberes anteriores de forma específica, mesmo entendendo que a seleção do vestibular tem nos conhecimentos específicos sua base. Assim, médicos, odontólogos, psicólogos, químicos, geógrafos, engenheiros, pedagogos, não demonstram suas habilidades anteriores e, afinal, também vão se especializar num curso de graduação. $\bigcirc$ quê eles têm de diferente? Qual a perspectiva de formação que está por trás disso?

O fato de ter no corpo seu objeto faz com que essas áreas precisem demonstrar, de antemão, essa experiência corporal? A dimensão da prática estaria sendo 
exigida por antecedência nos cursos de dança, porque tem como instrumento o próprio corpo?

Nos estudos sobre dança, tem-se apontado como necessário um profissional que seja um "artista-docente", um professor que tenha uma formação artística sólida para não separar a arte da educação. Marques (1999, p. 19) questiona:

Como fazer com que a atuação do professor de dança na escola não se dissocie do artista que é/deveria ser? e, ainda, O professor que não teve experiência artística na área de dança pode levar o aluno a dançar? Quais são os limites de uma formação que visa primordialmente à educação em detrimento da arte? (MARQUES, 2003, p. 103).

Inúmeros estudos na educação física questionam se o professor deveria ser um atleta ou um ginasta, ou mesmo se este deveria formar atletas em suas aulas, discordando dessa visão. Um professor deve conhecer a gestualidade específica, deve ter conhecimentos técnicos, porém não necessariamente ser um atleta. Essa perspectiva de análise diferencia-se da arte que aponta que o professor deve ser um artista em potencial para poder exercer a profissão de professor.

Fortin (2003, p. 162), ao refletir sobre as transformações da dança, enfatiza que

[...] a dança não pode existir sem o corpo. $\bigcirc$ corpo em movimento constitui a própria matéria da dança. A obra do artista se incorpora em sua carne. De todos os artistas, os intérpretes de dança são os únicos que não se livram jamais de seu instrumento de trabalho,

podemos dizer o mesmo dos atletas, dos ginastas, dos capoeiristas, etc.

É importante diferenciar, no entanto, que para ser dançarino, atleta, ginasta, capoeirista, não é necessária uma formação superior. Essas formações acontecem em espaços distintos, como clubes, academias, estúdios, associações, ruas, etc. Chegam às universidades umas poucas pessoas entre as que tiveram esse processo formativo.

A maioria que se insere nos cursos de Educação Física tem registrado uma experiência com modalidades esportivas, com lutas, com danças, com técnicas corporais, mas outros sequer têm relação com a área, são pessoas que têm interesse em trabalhar com questões ligadas ao corpo, à escola, ao jogo, etc. Enquanto nos cursos de Dança, pelo sistema de avaliação atual, só entrará quem comprovar essa experiência anterior.

A discussão presente na Educação Física sobre rendimento, esportivização, performance, aparece nos cursos de Dança, conforme citado na apresentação de um dos testes de habilidades. Exigir do aluno uma performance de atleta diz do lugar que seu corpo ocupará nesse processo. Tomar a experiência do aluno como referência para sua formação é diferente de tomá-la como definidor de sua continuidade de formação. Acredito que a Educação Física acertou quando excluiu os 
testes de habilidades de sua seleção, pois isso indica que o corpo, tomado como objeto, não precisa ser um corpo atlético para ser professor, já que conhecer sobre os gestos técnicos permitirá ao professor dominar sua profissão; contudo, ele não precisará ser um atleta para isso. Compreendo que o mesmo deveria ocorrer com a dança, pois para ser um professor de dança se faz necessário conhecer os gestos técnicos e artísticos, porém não necessariamente ser um dançarino em potencial, o que não impede reconhecer que isso qualifica, também, essas formações, seja na Educação Física, seja na Dança.

Até aqui, refleti sobre o fragmento tematizado tomando a questão do corpo como objeto na dança. Mas, e quanto ao corpo como instrumento profissional na dança? Anteriormente, levantei como questão: "A dimensão da prática estaria sendo exigida por antecedência, nos cursos de dança, porque ele tem como instrumento o próprio corpo?" Mas o quê significa ser o corpo um instrumento profissional?

\section{O QUÊ SIGNIFICA SER O CORPO UM INSTRUMENTO PROFISSIONAL?}

Aqui, parece-me que ao falar de instrumento está se tratando de algo a ser utilizado; nesse caso, o corpo é usado pelo professor e pelo dançarino para dançar e ensinar dança, sendo o corpo seu próprio instrumento de ação e intervenção. Fica a ideia de que na pintura o pintor usa telas, pincéis e tintas como seus instrumentos, em um jogo de futebol será a bola, em uma partida de tênis será a raquete e sua bola específica, e na dança não há esse instrumento externo, será o próprio corpo seu instrumento. Neste caso, objeto e instrumento em dança encontram-se, são o corpo.

Nessa reflexão, reconheço a presença da ideia de experiência corporal. E para refletir sobre a ideia de experiência, recorro a Benjamin ( 1987 ) com a intenção de identificar a dimensão corporal da experiência. Em "Experiência e pobreza", o autor recupera a parábola de um velho que, no momento de sua morte, transmite aos seus filhos "uma certa experiência" sobre a vida, pois:

\footnotetext{
Sabia-se exatamente o significado da experiência: ela sempre fora comunicada aos jovens. De forma concisa, com a autoridade da velhice, em provérbios; de forma prolixa, com a sua loquacidade, em histórias, muitas vezes como narrativas de países longínquos, diante da lareira, contadas a pais e netos. Que foi feito de tudo isso? Quem encontra ainda pessoas que saibam contar histórias como elas devem ser contadas? Que moribundos dizem hoje palavras tão duráveis que possam ser transmitidas como um anel, de geração em geração? Quem é ajudado, hoje, por um provérbio oportuno? Quem tentará, sequer, lidar com a juventude invocando sua experiência? (BENJAMIN, 1987, p. I|4).
}

Destaca que a pobreza da experiência é de toda a humanidade, como uma barbárie que impede o ser humano de caminhar, de ir além. E ao fazer observações 
sobre a obra de Nicolau Lescov, afirma que parece que perdemos o poder de trocar experiências vividas, através das narrativas. Para ele "[...] as ações da experiência estão em baixa, e tudo indica que continuarão caindo até que seu valor desapareça de todo" (BENJAMIN, 1987, p. 198).

Benjamin (1987, p. 198) fala de narrativas orais contadas por diversos sujeitos, seja o narrador que vem de longe, na perspectiva de "quem viaja tem muito que contar", como os viajantes, comerciantes, marinheiros, seja o narrador que, não saindo de seu país, está imbuído de suas histórias locais, aquele que conhece as estórias e tradições de seu lugar, situando os camponeses locais. Esse narrador tem como fonte a experiência que passa de pessoa a pessoa através da oralidade, com especial destaque aos velhos, que têm experiências de outras gerações.

As experiências oriundas da tradição oral vão ganhar, com a análise da obra de Paul Valéry, ${ }^{4}$ a presença da alma, dos olhos e da mão, o que indica que

A narrativa como forma de comunicação da experiência supõe a presença corporal daquele que narra aos ouvintes. Palavras e gestos fazem parte da narração, que deve começar com um relato sobre o contexto do acontecido" (VAZ, 200I, p. 47).

Dessa forma, o narrador só mantém viva sua experiência porque existe o outro: o ouvinte, o seu interlocutor, um sujeito que se envolve com sua comunicação e interage com ele, através de sua palavra e de seu gesto, de seu corpo.

Benjamin (1987, p. 220-22 I) reconhece que Paul Valéry estabeleceu "afinidades entre alma, olho e mão", ao escrever sobre a observação do artista. Afirma ele:

O papel da mão no trabalho produtivo tornou-se mais modesto, e o lugar que ela ocupava durante a narração está agora vazio. (Pois a narração, em seu aspecto sensível, não é de modo algum o produto exclusivo da voz. Na verdadeira narração, a mão intervém decisivamente, com seus gestos, aprendidos na experiência do trabalho, que sustentam de cem maneiras o fluxo do que é dito.) A antiga coordenação da alma, do olhar e da mão, que transparece nas palavras de Valéry, é típica do artesão, e é ela que encontramos sempre, onde quer que a arte de narrar seja praticada. Podemos ir mais longe e perguntar se a relação entre o narrador e sua matéria - a vida humana - não seria ela própria uma relação artesanal. Não seria sua tarefa trabalhar a matéria-prima da experiência - a sua e a dos outros - transformando-a num produto sólido, útil e único? Talvez se tenha uma noção mais clara desse processo através do provérbio, concebido como uma espécie de ideograma de uma narrativa. Podemos dizer que os provérbios são ruínas de antigas narrativas, nas quais a moral da história abraça um acontecimento, como a hera abraça um muro.

4. Paul-Ambroise Valery (Sete, I87| - Paris, 1945) interrogou-se obstinadamente, desde a juventude, sobre a natureza do pensamento, seu funcionamento, seus limites. Sua obra poética é considerada uma das mais importantes da poesia francesa do século $X X$. 
A narrativa, que tem na experiência seu eixo, está situada na experiência humana. Assim, os sujeitos narram suas vidas pelas palavras e gestos, nas quais "[...] o narrador figura entre os mestres e os sábios. Ele sabe dar conselhos: não para alguns casos, como o provérbio, mas para muitos casos, como o sábio". Dessa forma, ele mantém a interação social viva,

Pois pode recorrer ao acervo de toda uma vida (uma vida que não inclui apenas a própria experiência, mas em grande parte a experiência alheia. $\bigcirc$ narrador assimila à sua substância mais íntima aquilo que sabe por ouvir dizer) (BENJAMIN, 1987, p. 221),

o que para Bakhtin (2003, p. 27I), é a existência de um falante e um ouvinte que justifica essa interação, em que ambos têm uma posição responsiva, visto que

Toda compreensão da fala viva, do enunciado vivo é de natureza ativamente responsiva (embora o grau desse ativismo seja bastante diverso); toda compreensão é prenhe de resposta, e nessa ou naquela forma a gera obrigatoriamente: o ouvinte se torna falante.

A narrativa é, para Benjamin (1987, p. 205), "[...] num certo sentido, uma forma artesanal da comunicação", em que sua intenção está além de "[...] transmitir 'o puro em si' da coisa narrada como uma informação ou um relatório". Nesse sentido, "ela mergulha a coisa na vida do narrador para em seguida retirá-la dele. Assim se imprime na narrativa a marca do narrador, como a mão do oleiro na argila do vaso" (BENJAMIN, 1987, p. 205).

Essa experiência construída socialmente, não é individualizante e nem solitária, e sim social, faz com que os sujeitos façam escolhas conscientes. De tal modo, os sujeitos que chegam aos cursos de Educação Física e Dança têm em seus corpos experiências corporais e artísticas inscritas de outros tantos espaços em que eles foram ouvintes/apreciadores ou narradores/produtores, e ao se inserirem em um curso de formaçãa, trarão essas experiências, colocando-as em diálogo com as outras experiências dos sujeitos nele envolvidos.

Como alerta Fontana (2005), eles chegam aos cursos de formação em um percurso que não pode ser considerado uma questão de dom, nem sorte, nem vocação, e sim de identificação e aprendizado. Ao entrar em um curso de formação fazemos uma escolha, o que implica questionar: "E como é que se escolhe? O que antecede e o que possibilita que se faça uma escolha? $O$ que começa com a escolha feita, se ela, por sua vez, nasce de outras escolhas, de determinações e até de acasos? Não passa por aí a história que cada um de nós 'é'?" (FONTANA, 2005, p. 84).

Para Benjamin (1987), a experiência se constitui em torno do trabalho manual, como se cada um de nós fosse fiando, tecendo sua história. Todos os sujeitos que 
se inserem nos cursos de Educação Física e de Dança possuem experiências singulares, que foram tecidas em constante interação com outros sujeitos, em diferentes locais e tempos, e nesse processo, continuam fiando a história com a qual chegam a esses cursos. Vão se fazendo professores de Dança e de Educação Física nesse novo espaço e tempo de formação, em que o vivido será retomado o tempo todo, pois ele os constitui, e diante do contato com o conhecimento científico, com as salas de aula, com os alunos nas escolas, ampliam suas experiências, permitindo compreender que se tornar professor ou professora de Dança ou de Educação Física se faz nesse contínuo processo de constituição.

\section{In Dance the Object and Professional Instrument is the Own Body}

ABSTRACT: The present study is a fragment of the thesis Dance - Physical Education: (in) tense relations, analyzing senses and meanings derived from curricular standards in teacher education courses, in Physical Education and Dancing, concerning dancing knowledge. It is characterized as a documental research whose main source are the pedagogical projects of Dancing and Physical Education courses, including a pair in Bahia (UFBA) and other in São Paulo (UNICAMP). By analyzing the pedagogical projects we identified that the body has an outstanding presence, being the dimension of the body its biggest focus. But what means for an area of knowledge having the body as its foundational reference?

KEYWORDS: Dance; Physical Education; body; formation

\section{En la danza el object e su instrument professional es el cuerpo}

RESUMEN: El presente estudio es un fragmento de la tesis Danza - Educación Física: (in) tenses relaciones, que tenía por objeto analizar los sentidos y los significados producidos en el proyecto de plan de estudios para cursos de formación para profesores de educación física y danza respecto al conocimiento danza. Caracterizado como una investigación documental que tuvo como principal fuente los proyectos de enseñanza de los cursos de Licenciatura en Danza y en Educación Física, se delimitó un par proveniente de lo Estado de Bahia (UFBA) e otro de São Paulo (UNICAMP). Mediante el análisis de los proyectos pedagógicos identificó que el cuerpo tiene una presencia notable, tiene la dimensión del hacer cuerpo su mayor concentración. Sin embargo, lo que significa para una área que tiene el cuerpo como referencia fundacional?

PALABRAS-CLAVE: Danza; Educación Física; cuerpo; formación.

\section{REFERÊNCIAS}

BAKHTIN, M. Estética da criação verbal. 4. ed. São Paulo: Martins Fontes, 2003. 
BENJAMIN, W. O narrador: cosiderações sobre a obra de Nikolai Leskov. In:

Magia e técnica, arte e política: ensaios sobre a literatura e história da cultura. 3. ed. São Paulo: Brasiliense, 1987. p. 197-221.

Experiência e pobreza. In: - Magia e técnica, arte e política: ensaios sobre a literatura e história da cultura. 3. ed. São Paulo: Brasiliense, 1987. p. | |4- | 19. FONTANA, R. A. C. Ler o corpo que ensina - uma aproximação dos efeitos de sentido dos gestos de proximidade corporal entre professoras e crianças das séries iniciais do ensino fundamental. In: CONGRESSO DE LEITURA DO BRASIL, 16., 2007. Anais... Campinas: COLE, 2007. p. I-9.

Como nos tornamos professoras? Belo Horizonte: Autêntica, 2005.

FORTIN, S. Transformação de práticas de dança. Lições de Dança. Rio de Janeiro: UniverCidade, 2003. p. |6|-|73. v. 4.

FRAGA, A. B. Anatomias emergentes e o bug muscular: pedagogias do corpo no limiar do século XXI. In: SOARES, C. L. (Org.). Corpo e história. Campinas: Autores Associados, 2001 . p. $61-77$.

HAROCHE, C. Da palavra ao gesto. São Paulo: Papirus, 1998.

MARQUES, I. Dançando na escola. São Paulo: Cortez, 2003.

Ensino da dança hoje: textos e contextos. São Paulo: Cortez, 1999.

REVEL, J. Os usos da civilidade. In: CHARTIER, R. História da vida privada - 3: da renascença ao século das luzes. São Paulo: Companhia das Letras, I991. p. 169-209.

SANT'ANNA. D. B. É possível realizar uma história do corpo? In: SOARES, C. L (Org.). Corpo e história. Campinas: Autores Associados, 200 I. p. 3-23.

SENNET, R. Carne e pedra: o corpo e a cidade na civilização ocidental. Rio de Janeiro: Record, 1997.

SILVA, A. M. Prefácio. In: SOARES, C. L. (Org.). Pesquisas sobre o corpo: ciências humanas e educação. Campinas: Autores Associados, 2007. p. xi-xiv.

SOARES, C. L. Imagens da educação no corpo: estudo a partir da ginástica francesa no século XIX. Campinas: Autores Associados, 1998.

TERRA, V. D. S. Memórias anatômicas. 2007. 198 f. Tese (Doutorado em Educação) - Faculdade de Educação, Universidade Estadual de Campinas, Campinas, 2007.

UNIVERSIDADE FEDERAL DA BAHIA (UFBA). Departamento de Educação Física. Reestruturação do Curso de Licenciatura Plena em Educação Física. Salvador: UFBA, 2007.

UNIVERSIDADE FEDERAL DA BAHIA (UFBA). Escola de dança: reconstrução curricular. Salvador: UFBA, 2004. 
UNIVERSIDADE ESTADUAL DE CAMPINAS (UNICAMP). Coordenação de Graduação em Dança. Projeto Pedagógico do Curso de Graduação em Dança. Campinas: UNICAMP, 2006.

UNIVERSIDADE ESTADUAL DE CAMPINAS (UNICAMP). Faculdade de Educação Física. Projeto Pedagógico dos novos currículos dos cursos de Educação Física: Licenciatura em Educação Física e Graduação em Educação Física. Campinas: UNICAMP, 2005.

UNIVERSIDADE ESTADUAL DE CAMPINAS (UNICAMP). Portal da Unicamp. Disponível em: http://www.unicamp.br/unicamp/divulgacao/indice/2008/I. Acesso em: 24 de janeiro de 2008 .

VAZ, A. F. Memória e progresso: sobre a presença do corpo na arqueologia da modernidade em Walter Benjamin. In: SOARES, C. L (Org.) Corpo e história. Campinas: Autores Associados, 2001. p. 43-60.

Recebido em: 31 mar. 20 I I

Aprovado em: I4 nov. 20। I

Endereço para correspondência: Lívia Tenorio Brasileiro Rua Setubal, 1256, apto. 101 Bairro Boa Viagem Recife-PE CEP: 51030-0I0 